ENSINO E PESQUISA EM ADMINISTRAÇÃO 


\title{
FORMAÇÃO DE PROFESSORES DE ENSINO SUPERIOR PARA A GESTÃO: PERSPECTIVAS E CONSEQUÊNCIAS
}

\author{
HIGHER EDUCATION TEACHER TRAINING FOR MANAGEMENT: \\ PERSPECTIVES AND CONSEQUENCES
}

Milka Alves Correia Barbosa

Universidade Federal de Alagoas

Maria Teresa Geraldo Carvalho

Universidade de Aveiro

Fernanda Roda de Souza Araújo Cassundé

Universidade Federal do Vale do São Francisco
José Ricardo Costa de Mendonça

Universidade Federal de Pernambuco
D2 2017 . Universidade FUMEC / FACE. Prof. Dr. Henrique Cordeiro Martins. Prof. Dr. Cid Gonçalves Filho.

\section{RESUMO}

O trabalho buscou analisar como professores de uma universidade federal brasileira percebem o papel que as políticas públicas e organizacionais têm na formação dos academic-managers.Argumenta-se que diante dos papeis-chave que os professores-gestores desempenham nas instituições de ensino superior, entende-se que há necessidade de políticas públicas (PP) e políticas organizacionais (PO) voltadas a formação desses atores. A investigação, baseada num estudo de caso, adotou uma perspectiva qualitativa e os dados foram coletados a partir de entrevistas semiestruturadas realizadas com professores-gestores do nível estratégico da Universidade Federal do Vale do São Francisco (Univasf). Em resposta ao objetivo geral desta pesquisa, os dados mostraram que os professores nesta universidade percebem uma lacuna de PPs e POs que os prepare para desempenhar o papel de gestor e apontam fatores como a temporalidade do papel de gestor, a priorização dos papéis de professor e de pesquisador sobre o de gestor, podem ser tomados como possíveis entraves ao desenvolvimento de tais políticas.

\section{PALAVRAS-CHAVE}

Formação de Professor-gestor. Políticas Públicas. Políticas Organizacionais. Universidade. 


\section{ABSTRACT}

The study sought to analyze how teachers of a Brazilian federal university realize the role that public and organizational policies have in the formation of academic-managers. It is argued that in view of the key roles that academic-managers play in higher education institutions, it is understood that there is a need for public policies (PP) and organizational policies (OP) aimed for training these actors. The research, based on a case study, adopted a qualitative approach and data were collected through semi-structured interviews conducted with e strategic-level academic-managers of Federal University of São Francisco Valley (UNIVASF). In response to the general objective of this research, the data showed that teachers at this university perceive a lack of PPs and OPs to prepare them to play the role of manager and pointed factors such as the temporality of the role of academic-manager, the prioritization of the roles of teacher and researcher on the manager can be evoked to explain the potential barriers to the development of such policies.

\section{KEYWORDS}

Academic-manger Training. Public Policies. Organizational Policies. University.

\section{INTRODUÇÃO}

O contexto do trabalho no ensino superior tem sofrido transformações significativas nas últimas três ou quatro décadas, decorrentes de mudanças econômica, sociais e tecnológicas, impactando no comportamento dos atores envolvidos nesse contexto. Mais especificamente, a globalização e as mudanças no modo de produção capitalista (do fordismo à acumulação flexível) foram respostas encontradas pelas sociedades capitalistas para a retomada do crescimento econômico após o fim do ciclo de expansão iniciado no período pós Segunda Grande Guerra.

Nesse cenário, pressões globais foram direcionadas a implementação de reformas educacionais que assegurem a formação de força de trabalho adequada às exigências de uma nova economia (SANTIAGO;
CARVALHO, 20I I). As instituições de ensino superior (IES), inclusive as públicas, foram chamadas a mostrarem à sociedade que podem fazer o uso eficiente e eficaz de recursos e que suas atividades são relevantes para o mercado de trabalho e para a economia. Particularmente influentes nessas pressões estão a Nova Gestão Pública (NGP) e a ideologia gerencialista (CARVALHO; BRUCKMANN, 20I4; DEEM; HILLYARD; REED, 2007; FROLICH, HUISMAN, SLIPERSATER et al., 20l3), as quais pressupõem que a gestão privada é mais eficiente que a pública, considerando-a, juntamente com os gestores, os pilares sob os quais se apoiam a economia, a política e a ordem social (SANTIAGO; CARVALHO, 20I2).

Em especial, o Gerencialismo, mesmo com possíveis variações entre países e se- 
tores (CARVALHO; BRUCKMANN, 20I4), trouxe mudanças à relação entre Universidade e Estado, assumindo este último caráter avaliativo (NEAVE, 1998), caracterizado pela delegação da gestão operacional, o fortalecimento do papel da liderança dentro da Universidade, a transferência do orçamento para as instituições, bem como a definição de contratos e metas a serem alcançados (BRAUN, 20I4; NEAVE, I 998). Semelhante ao que foi encontrado por outros pesquisadores em seus trabalhos sobre o ensino superior na Europa (DEEM, HILLYARD, REED, 2007; FROLICH, HUISMAN, SLIPERSATER et al., 20I3; MUSSELIN, 20I3), no contexto do ensino superior brasileiro os valores apropriados da Administração de empresas privadas, tais como eficiência, eficácia e competição também se evidenciam (VALENTIM; EVANGELISTA, 20I2).

Outra demanda do gerencialismo é a profissionalização da administração da universidade, acompanhada da busca pela racionalidade econômica, pela demanda por avaliação mais detalhada da performance profissional por meio de mecanismos de accountability. Entretanto, há um fato a se considerar, as IES têm sido gerenciadas por professores e não por administradores profissionais. Ademais, é importante reconhecer que a gestão da universidade por professores tem sido considerada como uma das principais condições para assegurar a autonomia acadêmica.

Nesse novo contexto, "sob a nova pressão gerencialista", a reputação dos acadêmicos não é baseada apenas em seu desempenho nos tracionais papéis de docente e de pesquisador, mas também no desempenho com base em suas capacidades de gestão (MEEK, GOEDEGEBUURE,
SANTIAGO et al., 20I0). Assim, verifica-se a tendência de substituir os valores acadêmicos pelos econômicos, questionando o tradicional perfil do professor de ensino superior como profissional autônomo, sustentado por seu saber, conhecimento e habilidades para transmitir seus saberes.

No Brasil,oArt. $3^{\circ}$ do Decreto 94.664187 prevê a gestão universitária como uma atividade própria do professor do ensino superior, juntamente com o ensino, a pesquisa e a extensão. Assim, quando o professor atua no papel de gestor universitário, quer seja como reitor ou pró-reitor, por exemplo, ele pode ser considerado como academic-manager (DEEM, 2004; SANTIAGO, CARVALHO,AMARAL et al., 2006).

$O$ academic-manager pode ser definido como uma espécie particular de gerente, com funções e papéis peculiares ao mundo acadêmico, na medida em que são, antes de tudo, em geral, professores de carreira (ÉSTHER; MELO, 2008). Observando particularmente o contexto das universidades federais brasileiras é possível identificar o aumento das expectativas sobre o academic-manager na medida em que se espera que esse sujeito desempenhe uma miríade de atividades administrativas além de atuar simultaneamente como educador, líder educacional, representante da instituição perante o público em geral, líder administrativo e coordenador-geral, dentre outras (CUNHA, 1999).

Nessa dinâmica, é importante lembrar que os atuais academic-managers, na maior parte dos casos, não foram preparados para assumir papéis gerenciais em instituições de ensino superior (IES). $O$ fato é que há uma lacuna na formação desses indivíduos devido à ausência de treinamento formal que anteceda à atuação dos indivíduos es- 
colhidos para as funções gerenciais na universidade (CAMPOS, 2007; SILVA, 20I2).

No âmbito das universidades federais brasileiras, esse hiato na preparação de gestores torna-se ainda mais significativo conquanto trata-se de instituições sob influência direta das políticas públicas e nas quais os gestores atuam cumprindo regras e diretrizes de órgãos públicos diversos, tais como o Ministério da Educação (MEC), Coordenação de Aperfeiçoamento de Pessoal de Nível Superior (CAPES), dentre outros.

Tomando-se como ponto de partida esses aspectos introdutórios, este propõe-se a analisar como professores de uma universidade federal brasileira percebem o papel que as políticas públicas e organizacionais têm na formação dos academic-managers. Para tanto, na seção 2 caracteriza-se o academic-manager; na seção 3, apresentam-se algumas reflexões teóricas sobre políticas públicas e políticas organizacionais voltadas à formação desse sujeito para a gestão. $\mathrm{Na}$ sequência, apresentam-se a abordagem metodológica adotada na pesquisa. Seguese apresentando e analisando os dados coletados e, por fim, apontamentos a título de considerações finais.

\section{Academic-manager}

Como mencionado anteriormente, é amplamente reconhecido que novos desafios e pressões são colocados aos professores de ensino superior. À expansão, à massificação, ao declínio no status socioeconômico desse nível de ensino, adicionase as mudanças na relação entre Estado e IES devido a emergência de influências neoliberais e do gerencialismo (ENDERS; MUSSELIN, 2008).

De sujeitos autônomos envolvidos com a pesquisa, o ensino e responsáveis por organizar seu tempo e o peso para cada atividade, os professores estão se tornando trabalhadores acadêmicos com o aumento do controle gerencial sobre suas atividades, a pressão por resultados que impulsionam o desenvolvimento institucional ou nacional e a introdução de incentivos para encorajar certos tipos de comportamento e desempenho (MUSSELIN, 20 I3).

Nesse contexto, atividades que antes eram consideradas secundárias ou periféricas pelos professores hoje são reconhecidas por sua importância, notadamente as atividades de gestão. Trata-se de atividades que não são apenas algo mais que $\circ$ professor pode fazer, mas sim que ele deve fazer (ZABALZA, 2007). Assim, esses sujeitos são cada vez mais orientados a assumir posições de gestão, as quais exigem mais tempo e habilidades específicas deles.

Tal como mostraram Campos, Campos, Souza et al. (2008) e Silva (20I2), quando passam a ser gestores, os professores deixam de se preocupar somente com seus alunos, e ocupam-se também da "coordenação de seus pares, a regulação e conflitos, a supervisão, em detrimento da realização direta de trabalhos técnicos" (SILVA, 20I2, p. 4). Ao acumular as atividades acadêmicas com as gerenciais, esse sujeito passa a ser um gestor, sendo comumente chamado nos trabalhos sobre o tema de "professorgerente", "professor-gestor" e que neste trabalho corresponde ao professor-gestor (academic-manager).

Mesmo com considerável variação, a trajetória mais comum a esses academicmanagers é iniciar atuando em suas áreas de formação para atender aos interesses de seu curso, departamento, colegiado ou centro e aos poucos ir se envolvendo 
em outros níveis hierárquicos (MORAES, 2008). A esse respeito, Silva e Cunha (2012) explicam que a experiência dos acadêmicos em cargos de dirigente constitui-se numa transição vivida pelos mesmos, os quais passam de contribuidores individuais a líderes. $\mathrm{Na}$ primeira situação, eles assumem o papel de um especialista, um produtor ou um profissional que realiza tarefas técnicas específicas e sua colaboração para com a universidade depende acima de tudo de sua competência, experiência e energia. Eles são responsáveis apenas por suas atividades e tarefas específicas. Como líder, quer seja no papel de reitor ou de pró-reitor, exercem influência sobre as atividades de várias pessoas, possuindo uma agenda imprevisível e dependente de necessidades alheias.

Diferentes autores têm tentado descrever as atividades relacionadas ao academic-manager. Nessa perspectiva, podem-se apontar alguns delas tais como o de influenciar políticas institucionais e procedimentos; recomendar acadêmicos para cargos e mandatos; controlar orçamento, turmas e avaliação docente e discente, entre outros (CARROLL; WOLVERTON, 2004). Portanto, esse papel incorpora substancial poder e responsabilidade.

Além de reconhecer a importância desses professores na gestão do sistema de ensino superior, Melo, Lopes e Ribeiro (2013) e Miranda (2010) defendem a necessidade de políticas públicas e políticas organizacionais visando o desenvolvimento de competências de gestão acadêmicos, capaz de dar apoio institucional aos mesmos acadêmicos no exercício das suas atividades administrativas, e facilitar a integração entre ser professor e ser um gerente.

\section{Políticas públicas e organizacionais de apoio à formação dos academic-managers}

Entendendo que a gestão universitária tem nuances que a diferenciam, conferindo-lhe peculiaridade e complexidade, argumenta-se que a universidade não pode e nem deve ser gerenciada como uma empresa (ÉSTHER, 20I0). Enquanto na gestão empresarial, o lucro é a finalidade dos empreendimentos, o mesmo não se pode afirmar categoricamente quando se trata de uma universidade, por exemplo, posto que há muito mais ambiguidade sobre o que seria o apropriado nessas IES (O'CONNOR; CARVALHO, 20I5).

De fato, certas características das IES representam desafios ao desempenho do papel de gestor. Dentre elas a presença de canais formais de comunicação e da impessoalidade nas inter-relações, objetivos e resultados diversos e ambíguos, estrutura organizacional complexa e fragmentada, processo de tomada de decisão organizado em torno da produção de conhecimento, além da constante tensão entre ideias e práticas inovativas e resistente a mudança, ao mesmo tempo (BLEIKLIE; ENDERS; LEPORI, 20I3).

Dados esses aspectos, entende-se que a gestão universitária é um trabalho para o qual igualmente se espera do professor de ensino superior qualificação e preparação específicas tanto quanto para as atividades de ensino, de pesquisa, de orientação ou de extensão. Nessa direção, o presente trabalho tem como objetivo compreender a percepção dos academic-managers sobre o papel que as políticas públicas e organizacionais devem ter na formação de professores que executam funções dos gestores em IES. 
Neste texto, entende-se que as Políticas Públicas (PP) de Ensino Superior definem direitos e deveres, preferências, objetivos, princípios e formas de organização do nível terciário de Educação (MOROSINI; BITTAR, 2006). Sendo assim, sua influência sobre o papel dos professores-gestores é mais indireta do que direta. Observe-se, por exemplo, que nas últimas décadas os processos de expansão ampliaram o acesso ao ensino superior brasileiro a uma camada da população anteriormente excluída, alterando o cotidiano das IES, e exigindo de seus professores competências profissionais para buscar alternativas a situações que emergem desse novo contexto.

Já as políticas organizacionais (PO) são guias orientadoras da ação administrativa para o atingimento das metas e objetivos estabelecidos da organização (OLIVEIRA, 2006) e referem-se ao conjunto de ações sistemáticas no âmbito da IES que podem alterar a prática, as crenças e as competências profissionais dos professores.

Visto que as Políticas Públicas são, em geral, formuladas a partir de um fluxo top-down, por órgãos nacionais, Comarú (20II) alerta que fica a cargo de cada IES implementá-las por meio de políticas organizacionais próprias. Assim, ainda que operem em esferas diferentes de complexidade e direcionamento, as PP e as PO integram-se e podem viabilizar a formação de competências profissionais e gerenciais vinculadas a uma dada situação profissional e contexto.

Referindo-se ao processo de formação, no entendimento de Isaia (200I), há necessidade de espaços institucionais para que os professores se engajem em atividades de formação e desenvolvimento profissional. Especificamente tratando sobre a for- mação oferecida pela pós-graduação, Lourenço, Lima e Narciso (20l3) chamam a atenção para o fato de que tais programas ainda são organizados e orientados para a pesquisa. Desta forma, os egressos são susceptíveis de serem muito mais familiarizados com as atividades de investigação do que com o ensino e muito menos com a gerência.

Em virtude dos aspectos até aqui apontados, pode-se ainda afirmar que a maioria dos acadêmicos que atuam gestores universitários não vem sendo formada para assumir tais funções nas instituições de ensino e por isso grande parte deles é levada a improvisar em nesse papel (SILVA, 20 I2).

Pontuados esses aspectos, a seção seguinte apresenta a abordagem metodológica adotada na presente pesquisa.

\section{Aspectos Metodológicos}

presente estudo adotou uma perspectiva qualitativa, e como tal, buscou-se a obtenção de dados descritivos sobre pessoas, lugares e processos interativos, por meio do contato direto dos pesquisadores com a situação estudada, com vistas a compreender os fenômenos segundo a perspectiva dos sujeitos da situação em estudo (MINAYO, 2004).

Para o alcance do objetivo proposto para a pesquisa, realizou-se um estudo de caso baseado numa pesquisa qualitativa interpretativa básica. Esta modalidade de pesquisa tem se tornado comum em muitas áreas do conhecimento e campos aplicados, inclusive em Administração (GODOY, 2005).

Entendendo que o fenômeno em estudo envolvia uma articulação de conceitos e de níveis de análise caracterizada por uma temática ampla, pareceu adequado que algumas 
categorias de análise fossem definidas a priori, com base em definições constitutivas (DCs) (VIEIRA, 2004), enquanto outras emergiram a posteriori, quando da análise dos dados coletados, conforme mostra o quadro 0I:

A Universidade Federal do Vale do São Francisco (Univasf) foi escolhida como campo empírico da pesquisa e as razões da escolha desta instituição como um estudo de caso estão associadas ao seu caráter inovador. No que se refere a essa Ifes, destaca-se seu pioneirismo por ser a primeira universidade brasileira voltada para o desenvolvimento regional, decorrendo disso sua singularidade e assim, tanto retrata uma realidade quanto revela a multiplicidade de aspectos globais presentes no dado fenômeno em estudo (CHIZZOTTI, I 99I).

No que se refere aos participantes do estudo, não houve a preocupação em alcançar uma quantidade ideal de sujeitos, tendo em vista que a diretriz orientadora era escolher aqueles capazes de desenvolver alguma relação significativa com o fenômeno em estudo. Desta forma, foram entrevistados os indivíduos que constituíam o grupo considerado relevante para responder à questão de pesquisa, sendo possível afirmar que eles foram escolhi- dos de acordo com o critério da tipicidade (GASKELL, 20I0).

grupo de sujeitos da pesquisa foi formado por professores da Univasf que desempenham ou desempenharam o papel de professor-gestor no nível estratégico da instituição, nos últimos 10 (dez) anos, qual seja, reitor e ex-reitor; pró-reitores (atuais e anteriores) e respectivos substitutos; chefia de gabinete da reitoria (atual e anterior).

Importante destacar que houve a precaução de buscar participantes que já estiveram e outros que estão no papel de professor-gestor, para alcançar extensão dos pontos de vista e evitar o custo de escolher apenas aqueles que se enquadravam na perspectiva dos pesquisadores (MINAYO, 2004).

Como também, optou-se por pesquisar gestores da alta administração (reitores e pró-reitores), principalmente em função da escassez de estudos sobre este nível hierárquico, oportunamente detectada por Carvalho (20I4), Silva (20I2), dentre outros. Tendo em vista que se trata de uma jovem Ifes, achou-se oportuno adotar que o recorte temporal do estudo compreendesse desde a fundação da Univasf até os dias atuais.

\section{QUADRO 1 - Categorias de Análise definidas a priori e a posteriori}

\begin{tabular}{|c|c|}
\hline $\begin{array}{c}\text { Categorias de Análise } \\
\text { definidas a priori }\end{array}$ & Definição Constitutiva (DC) \\
\hline Política Pública (PP) & $\begin{array}{l}\text { Políticas de responsabilidade do Estado quanto à formulação, implementação e manutenção, } \\
\text { estabelecidas com base num processo de tomada de decisões que envolvem organismos da } \\
\text { sociedade política (Estado) e entidades da sociedade civil (HOFLING, 2001). }\end{array}$ \\
\hline $\begin{array}{c}\text { Política Organizacional (PO) } \\
\text { Categorias de Análise } \\
\text { definidas a posteriori }\end{array}$ & $\begin{array}{l}\text { Conjunto de premissas, programas e ações sistemáticas no âmbito da IES que visam } \\
\text { implementar as orientações e diretrizes das PP, possibilitando o desenvolvimento profissional } \\
\text { dos sujeitos, incluindo a formação de competências profissionais dos professores. }\end{array}$ \\
\hline $\begin{array}{l}\text { Interacão entre a pós graduação e } \\
\text { a formação do professor de ensino } \\
\text { superior para a gestão de IES }\end{array}$ & $\begin{array}{l}\text { Aspectos da política pública de pós-graduação que relacionem os cursos de mestrado e } \\
\text { doutorado à formação de professores do ensino superior para a gestão universitária }\end{array}$ \\
\hline
\end{tabular}

Fonte: Baseado em Hofling (2001) e na análise dos dados. 
Para coleta de dados, foram realizadas 22 (vinte e duas) entrevistas qualitativas semiestruturadas, com duração média de 56 minutos. Com esta técnica, buscou-se captar as ideias, sentimentos e forma de pensar do professor sobre o papel social de gestor.

As entrevistas foram registradas com gravador digital, seguindo a orientação de Alberti (2005), o qual afirma que tal equipamento "permite falar em produção de documento, no retorno à fonte, na montagem de acervos de depoimentos, na autenticidade de trechos transcritos e na análise de entrevista" (p. I I 2).

Em crescente utilização e legitimação nos estudos qualitativos em Administração (MOZZATTO; GRZYBOVSKI, 20II), a análise de conteúdo (AC) foi o procedimento utilizado para análise do corpus constituído por meio das entrevistas.

Dentre as técnicas classificadas por Bardin (20I I), no presente estudo utilizou-se a análise categorial, que consiste no desmembramento e reagrupamento do texto em categorias ou temas analógicos. $\mathrm{Na}$ presente pesquisa, a versão 7.5.6 do ATLAS/ti apoiou a análise dos dados, valendo-se das potencialidades dos softwares qualitativos para facilitar tal processo (BANDEIRADE-MELLO, 20 I0).

\section{Os dados analisados: a percepção dos academic-managers sobre formação para a gestão}

Ao se questionar os participantes da pesquisa, os sujeitos afirmaram, em unanimidade, que percebem não haver uma oferta sistematizada e articulada de políticas públicas (programas, ações) voltadas especificamente para a formação de gestores que atuam ou atuarão no peculiar contexto de universidades federais.
Em consonância com esta ausência, aos participantes foram oferecidos cursos sem continuidade e com conteúdo geral (para qualquer gestor público, independentemente da área ou tipo de instituição), como os oferecidos pela Escola Nacional de Administração Pública (ENAP). Estes dados revelam que a realidade apontada por estudos como os desenvolvidos por Soares e Cunha (2010) e Morosini (2000) não mudou como exemplifica o trecho de entrevista a seguir:

Não há um curso específico, não há uma política específica, nem no âmbito nacional a gente tem algumas iniciativas, mas elas são sempre pontuais. A gente não tem programas governamentais voltados para essa formação. A gente tem cursos que acontecem esporadicamente e que dependem também de quem está lá na gestão no momento[...]. PGIO

No nível de política organizacional, a percepção é semelhante: para os entrevistados, a oferta de algumas palestras ou mesmo cursos por órgãos internos da Univasf como os da Secretaria de Gestão de Pessoas (SGP) não pode ser configurado como um programa formal para a formação de acadêmicos para a gestão:

Aqui na universidade, a SGP, a Secretaria de Gestão de Pessoas, começou no início, mas de maneira muito tímida algumas manhãs de formação, mas depois não senti continuidade. $E$ não conheço uma política pública. Eu participei de uns dois ou três encontros desses da SGP, com o procurador, muito mais sobre a questão jurídica, que às vezes é um entrave [...]. PG5

Diante disso, percebe-se que não é possível caracterizar a Univasf como espaço de formação de competências gerenciais 
para seus gestores, conforme aconselham autores como Fleck e Pereira (20 I I) e Zabalza (2007). Atente-se que esse aspecto merece atenção dos formuladores das $\mathrm{PO}$ para averiguar possíveis problemas na concepção dessas ações de formação.

Sobre esse aspecto, segundo Zabalza (2007), a responsabilidade pela formação deve ser compartilhada entre a IES e o professor, e, portanto, as universidades devem encontrar saídas para a formação de sua força de trabalho, o que com certeza demanda a alteração de suas políticas organizacionais de administração de pessoal.

Em consequência da lacuna de PPs e POs, os entrevistados relatam que foram levados a aprender por conta própria, como desempenhar o papel de gestor, baseando-se em sua prática cotidiana e experiências anteriores, constituindo-se em um processo de caráter individual, informal e não institucional:

Se eu fiz algum curso, alguma capacitação? Não, a experiência mesmo é a vivência da comunidade acadêmica. Como eu sempre estudei em escola pública e universidade pública. Então eu sempre participava dessas discussões, na graduação, no mestrado, no doutorado. Sempre participei ativamente assim acompanhando o funcionamento de cada colegiado, cada departamento e tal. PGI3

Sendo assim, os relatos sinalizam que a formação dos professores da Univasf para o papel de academic manager está pautada basicamente em iniciativas individuais, caracterizando um desequilíbrio entre as forças que promovem a formação de competências profissionais: a formação educacional, a pessoa e a experiência profissional (LE BOTERF, 2003), sendo mantida a ênfase nas duas últimas, como exemplifica o seguinte relato:"Eu fico pensando assim, o que a gente poderia fazer no âmbito da Univasf, não sei se outras universidades... porque assim no meu caso foi mesmo de ir atrás, onde você pudesse encontrar ajuda”. PG3

Não obstante a percepção da lacuna, os fóruns promovidos pela Associação Nacional dos Dirigentes das Instituições Federais de Ensino Superior (ANDIFES) e pela Univasf são reconhecidos pelos entrevistados como potenciais espaços de formação informal, pois neles os academic-managers compartilham experiências, problemas, contribuindo para o desenvolvimento de algumas competências gerenciais:

[...] a gestão e o gabinete têm mantido até hoje outros ambientes de qualificação gerencial que são os fóruns. Os fóruns, por exemplo, lhe dão uma capacitação (não sei se é assim que se falaria), do ponto de vista das atitudes. Porque na interação com os outros colegas gestores você acabando compreendendo mais da organização que você participa, você vislumbra melhorias nos processos que você faz, e embora não seja, nos fóruns em que vai ser ensinado sobre procedimentos, mas eu diria que os fóruns reforçam competências gerenciais também, sabe? PG8

A certo ponto na análise de dados emergiu a necessidade de criar a categoria nominada de "interação entre políticas públicas de pós-graduação e formação de professores de ensino superior para a gestão”. Nesse sentido, a quase totalidade dos participantes afirmou que não vivenciou qualquer atividade voltada à tal finalidade durante o mestrado, doutorado ou pósdoutorado. Conteúdos relacionados a pe- 
dagogia universitária, gestão de instituições de ensino não foram apresentados a esses egressos, e, portanto, não se pode afirmar que a formação acadêmica inclui o contato com práticas direcionadas à formação de competências profissionais (gerenciais).

Ainda com relação à pós-graduação, os participantes relataram também fragilidades na formação de suas competências profissionais voltadas à docência e à pesquisa, alinhando-se a trabalhos de autores como Santos e Helal (20I3) Visto que esses mestres e doutores fazem parte de uma IES e lá serão chamados a atender uma miríade de atividades e papéis, é possível afirmar que esse hiato na pós-graduação vem afetando a atuação dos professores nos papéis de docente, pesquisador e extensionista, como evidencia a fala a seguir:

$\mathrm{Na}$ verdade, a nossa formação acadêmica ta tão distorcida que não forma nem professore, veja lá os professores-gestores! O mestrado... o mestrado e doutorado hoje praticamente inexistem cadeiras relacionadas a isto. Apesar de ter se pensado no início pra formar professores-pesquisadores, hoje fica assim: forma pesquisador, professor-pesquisador é outra história. PGI9

Além disso, os entrevistados também mencionaram a natureza específica da graduação e cursos de pós-graduação demasiadamente centrada no indivíduo e na dimensão técnica e científica, não oferecendo ferramentas relevantes para promover habilidades para resolver problemas de gestão, os quais são coletivos e altamente complexos:

Eu acho que a gente tem uma geração de professores que a formação foi: 04-05 anos de graduação, emeda- dos com 02 anos de mestrado, emendados com 04 anos de doutorado. Eu acho que esse profissional ele tem uma baita dificuldade de entrar nessa. A gente tem uma geração tipo tubo de ensaio. $O$ doutorado acho que cada vez mais se ensina técnica. Com isso ele acha que resolve tudo, e ai ele tem dificuldades na interação. Então eu acho que a gente tem cada vez mais uma formação que prepara para atividades individuais quando a gente tem o mundo onde os problemas cada vez mais são enfrentados coletivamente e uma coisa não tá fechando com a outra. $O$ cara sabe mexer com tubo de ensaio, sabe resolver as coisas dele, e sabe fazer uma compra individual para resolver os problemas da casa dele; ele não consegue na gestão PG8

Pode-se afirmar que as entrevistas corroboram a tendência de que, como egressos da pós-graduação stricto sensu, esses sujeitos também foram formados mais proficientes em atividades de pesquisa do que nas de ensino, enquanto as atividades de gestão tiveram menos ênfase. $O$ perfil dos professores-gestores entrevistados na Univasf justifica a preocupação de Cunha (20l2) com a formação do professor universitário, pois se trata de atores que atuam na gestão da Ifes sem formação específica voltada à tal apoiando-se na titulação obtida na pós-graduação e no conhecimento empírico acumulado em sua trajetória na instituição.

Tal achado é relevante, pois reforça a tradição de se ter como prioridade a formação para a pesquisa, dotando os alunos da pós-graduação stricto sensu de um perfil de pesquisador e de especialista em seus 
temas de estudo (MOROSINI, 2000; SILVA; COSTA, 20I4), mesmo sabendo-se que essas habilidades adquiridas em curso de doutoramento, por exemplo, não necessariamente preparam o professor para $\circ$ papel de dirigente de uma instituição de ensino superior (SILVA, 2000).

Diante dos aspectos aqui apresentados, acredita-se que, enquanto as políticas públicas de pós-graduação mantiverem o foco na valorização de competências de pesquisa e docência, a formação de professores para atuar na gestão de IES enfrentará dificuldades para prosperar e se institucionalizar nos programas de pósgraduação (PPGs).

Assumindo a necessidade de treinamento formal para desenvolver habilidades gerenciais, os entrevistados afirmaram que, mesmo a experiência e os processos de socialização informais, não são suficientes para lidar com o cotidiano da função gerencial posto que a formação individual não exclui a necessidade de políticas voltadas ao desenvolvimento de competências gerenciais, como afirmou o seguinte entrevistado: "Então eu acredito que o treinamento, a capacitação, podem fazer com que algumas habilidades mais técnicas, mais gerenciais sejam aprendidas, desde que você se disponha a aprender; esteja aberto ao novo". PG5

A defesa de iniciativas organizacionais para promover treinamento formal em gerenciamento está relacionada, principalmente, com as experiências dos academic -managers e, mais especificamente, com os problemas e dificuldades identificadas por eles. Estes discursos revelam que a existência de tais iniciativas seria percebida como positiva uma vez que poderia fazer a diferença no desempenho, levando-os a trabalhar menos com base no método de tentativa e erro, e experiência do passado (CAMPOS, CAMPOS, SOUZA et al., 2008; ÉSTHER, 2010), como mostra o relato a seguir:

Gente é uma perda de tempo, poderia dar um passo à frente. Se a gente utilizasse todas as técnicas de gestão, fazer a gestão do desempenho o aprendizado organizacional, na linha da capacitação e do treinamento, será que a gente, a tendência era melhorar isso muito, muito mesmo. PG3

Uma vez que os academic-managers da Univasf percebem a necessidade da existência de PPs e POs para formação de gestores seria relevante tentar entender por que este tipo de programas não foi criado até agora.

Nessa perspectiva, os relatos dão pistas sobre possíveis razões e dificuldades para reivindicar políticas públicas e organizacionais de formação de competências gerenciais. Dentre elas, parece que os papéis de gestão não estão incluídos na identidade dos professores como um grupo profissional. Os sujeitos da pesquisa relataram privilegiar a atuação em papéis que, na percepção deles, são de maior importância do que o de gestor, como o papel de pesquisador e o de docente, como se exemplifica nesse relato: "[ ...]agora no meu caso não, eu to trabalhando com uma coisa totalmente nova, que a maioria dos professores não quer fazer". PG I0

Nesse sentido, a análise de dados confirma estudos anteriores que revelam que os acadêmicos não consideram o papel do gerente como o foco de seus trabalhos em universidades (CAMPOS, CAMPO, SOUZA et al., 2008) ainda que formalmente 0 papel de gestor esteja previsto na carreira 
do magistério superior, como consta na Lei | 2772/20 I 2.Assim, apesar das pressões gerenciais, eles mantêm a sua identidade tradicional (SANTIAGO; CARVALHO, 20I2).

Ainda segundo os participantes, o tempo que o professor assume uma reitoria, pró-reitoria, coordenação ou chefia de departamento, em geral, não é suficientemente longo para exercer suas atividades corriqueiras e conseguir preparar-se para o papel de gestor, à semelhança do que foi mostrado na pesquisa de Silva (2012). Neste sentido, as funções de gerenciamento são assumidas principalmente como algo temporário, por um curto período de tempo. O relato a seguir ilustra tal reflexão: "Nós não somos gestores, nós somos professores, viemos para ser professores, a gestão ela vai, tem que, porque, professor tem que, o reitor tem que ser professor, já começa por aí". PGI4

Pesquisas anteriores também referiram que a gestão de exercício por um curto período de tempo não incentiva os acadêmicos a buscar uma formação mais específica (SILVA, 20I2). A análise dos dados revela que a Univasf está enfrentando um paradoxo. Embora existam demandas do gerencialismo para tornar as universidades mais eficientes, eficazes e responsáveis, exigindo mais competências de gestão, e os acadêmicos reconheçam a necessidade de formação em gestão, a identidade profissional permanece tradicionalmente mais associada às funções de ensino. Esta contradição traduz a ambivalência que grupo profissional enfrenta nos tempos atuais: eles assumem a sua legitimidade para desenvolver funções de gestão como uma forma de manter o seu poder e status levando a crescente presença de gestores, mas, também precisam garantir que o seu perfil tradicional dentro dessas instituições desde a profissão esteja associado principalmente com o papel de ensino dentro da divisão de trabalho.

O lugar secundário dado à gestão é também revelado no posicionamento dos entrevistados sobre a progressão na carreira, quando assinalam que a avaliação de desempenho muito mais baseada no ensino e na pesquisa. Na verdade, os academic-managers da Univasf não percebem as atividades de gerenciamento como tendo uma percentagem de pontuação tão atraente como pesquisa, ensino e extensão para a progressão na carreira.

Diante disso, é importante salientar que pensar em políticas públicas e políticas organizacionais para formação de professores de ensino superior para gestão quando o próprio sujeito não reconhece a relevância do papel de gestor, possivelmente torna a tarefa ainda mais difícil de ser cumprida. De outro ângulo, essa lacuna pode ser entendida como a não valorização institucional (em nível de PP e PO) do papel de professor-gestor, havendo um ciclo de retroalimentação entre ambos.

Por fim, os participantes sinalizaram como gostariam que fossem as ações voltadas à formação de competências gerenciais, no que concerne à estrutura, metodologia, conteúdo, conforme as categorias definidas por Zabalza (2007) para caracterizar uma política organizacional. Note-se que os entrevistados pontuam a necessidade de tais ações serem perenes e propostas com base nas atividades associadas ao papel de gestor de acordo com específica área de atuação de cada um, além de alinharem atividades teóricas e práticas,

Então acho que para que haja um plano de capacitação de gestores, ele tem 
que ser pontual mesmo. A depender da pasta tem que ter prioridades que são bem. Então precisaria ter um pra pesquisa, um pra extensão, um pra assistência estudantil. Customizado mesmo, porque quando é muito geral você termina desfocando. PG6

Com base nos dados analisados, pode-se afirmar que as tendências reportadas pela literatura para o ensino superior e para os papéis do professor não se concretizaram em políticas públicas para a formação desses sujeitos para a gestão. Além disso, não obstante tenham sido encontrados pontos de imbricamento entre PP e PO que caracterizam a interação entre esses dois níveis de política, no âmbito da Univasf, não se encontraram políticas organizacionais formalmente institucionalizadas voltadas à formação de seus dirigentes para a gestão universitária.

\section{Considerações Finais}

Este estudo teve como objetivo analisar como os academic-managers da Univasf percebem a importância de programas de formação formais para o desempenho do seu papel.

A análise dos dados mostrou que todos assumem a inexistência de programas de formação formais especificamente dirigidos para obter habilidades de gestão. Os programas de treinamento disponíveis assumem um perfil geral da administração pública, o que, segundo eles, não aborda as especificidades de uma universidade federal, como Univasf e as peculiaridades das atividades do papel de gestor.

Os dados analisados mostraram que as atuais PP ainda estão em estágio incipiente e não apresentam determinadas dimensões esperadas como ações ou redes interins- titucionais de formação, articulação entre pós-graduação e formação para gestão, inovações nos campos formativos, articulação entre formação do professor, melhoria da qualidade e desenvolvimento da educação, articulações entre os conhecimentos, habilidades e atitudes que constituem as atividades dos professores.

Como também, ao apontarem a ausência de políticas organizacionais da Univasf voltadas à preparação de seus professoresgestores, os relatos ratificam que o compartilhamento de conhecimentos, normas, procedimentos, regras de comportamento entre os professores-gestores da Univasf é precário e informal.

Ainda nessa perspectiva, para os participantes da pesquisa, a formação individual e/ou o desenvolvimento informal não exclui a necessidade de PP e PO de formação de professores gestores para a gestão universitária. Para os entrevistados, de fato, tal hiato traz transtornos ao desempenho no papel de gestor, levanto-os muitas vezes a erros, retrabalho, perda de tempo e recursos valiosos, os quais, na percepção dos sujeitos, poderiam ser minimizados caso tivessem uma formação adequada ao papel.

Além disso, os participantes reafirmaram que quase não há contribuição da formação recebida na pós-graduação para aqueles que ocuparão posições administrativas, denotando um desalinhamento entre as políticas organizacionais e as demandas impostas às IES pelas políticas públicas.

Isto é, apesar de haver uma necessidade crescente de políticas públicas para uma maior eficiência e eficácia em IES, alinhado com um processo de massificação e gerencialismo que exigem mais competências de gestão para ser capaz de desempenhar funções acadêmico-gerenciais, nas univer- 
sidades, em cuja missão inclui-se a oferta de programas de treinamento formal, não vêm sendo priorizadas oportunidades de formação para os academic-managers.

As principais razões para a incapacidade das universidades em definir e oferecer este tipo de programas podem estar relacionadas com o comportamento e identidade profissional dos acadêmicos; ao tentar lançar luz sobre esta ausência, os academic-managers apontam a temporalidade desse papel, reforçando que sua identidade profissional está mais associada a funções de ensino e pesquisa, nas quais eles tendem a ser mais concentrados. Assim, parece que, as ideias do gerencialismo ainda não foram capazes, no caso específico desta universidade, de mudar de identidade dos acadêmicos.

Aliás, mesmo com o aumento das demandas administrativas e de gestão e os academic-managers assumindo que programas de treinamento formal em gerenciamento seriam importantes para desempenhar o papel, esses mesmos sujeitos não se engajam para viabilizar tais políticas porque não assumem a gestão como parte de sua identidade profissional.

Em consonância com essa perspectiva, os entrevistados indicaram que apenas funções de ensino e pesquisa são avaliados e valorizados na avaliação de desempenho. Isto é, pouco reconhecimento e recompensas são dados para as tarefas administrativas, embora em alguns casos, elas representam uma porção significativa do tempo de trabalho.

A análise do caso específico da Univasf revela que a universidade ainda está em um processo de institucionalização e, como consequência, os acadêmicos tendem a associar esse processo à operacio- nalização diária da missão complexa de ensino, pesquisa e extensão das universidades, favorecendo o trabalho em funções às quais atribuem maior importância na sua identidade profissional.

Por outro lado, importa esclarecer que na Univasf, há pelo menos três instâncias - a Pró-reitoria de Ensino, a Pró-reitoria de Pesquisa, Pós-graduação e Inovação e a Secretaria de Gestão de Pessoas - que se propõem a cuidar da formação dos professores. Talvez caiba aqui o questionamento se essa configuração é mais adequada ou se acarreta sobreposições de funções, principalmente porque os sujeitos da pesquisa afirmaram categoricamente não contar com o suporte de $\mathrm{PO}$ que os prepare para o papel de professor-gestor.

Em virtude das escolhas metodológicas e epistemológicas, toda e qualquer pesquisa possui suas limitações. Pensar sobre elas é um momento de reflexão necessário ao pesquisador, no sentido de reconhecer quais outras rotas poderiam ter sido trilhadas ao longo da investigação. Neste estudo em particular, destaca-se o fato de que, ao se investigar uma única universidade federal perde-se um pouco da amplitude que poderia ser alcançada ao se ouvirem diversos indivíduos em diferentes IES. Por outro lado, com o estudo qualitativo básico ganhou-se em termos de profundidade na medida em que se conheceu uma realidade organizacional peculiar como a da Univasf.

De outra perspectiva, a melhor forma de trabalhar as limitações de uma pesquisa é promover novos estudos, de modo a buscar respostas para perguntas que não foram eventualmente bem aprofundadas, ou para novas questões que emergiram dos resultados então apresentados. Assim, sugerem-se alguns tópicos para pesquisas 
futuras, alinhadas ao tema central desta pesquisa, com possibilidades de extensão, aprofundamento e comparações do estudo ora realizado:

a) nesta investigação, partiu-se do pressuposto de que se a IES oferecer oportunidades para formação de competências, os professores participarão. Em instituições com políticas organizacionais de formação institucionalizadas, os professores, de fato, se fizeram presentes? Ou houve evasão nos cursos de formação gerencial? Qual a percepção desses sujeitos acerca da formação?;

b) no presente estudo, ouviramse os professores sobre a lacuna de PP e PO formação de competências gerenciais. Todavia, parece-nos igualmente frutífero ouvir outros atores institucionais, tais como os planejado- res de políticas públicas em instância como o MEC, CNPq, Andifes, Capes;

c) em se reconhecendo $o$ avanço do modelo empresarial em IES em países da Europa (MUSSELIN, 2013; CARVALHO, 20I4), uma agenda promissora seria estudar esse fenômeno em IES públicas brasileiras, e sua repercussão no papel do professor-gestor;

d) à semelhança da presente investigação, caberia ainda um estudo comparativo, quer seja com outras instituições de perfil análogo à Univasf, ou instituições mais antigas.

Espera-se que este trabalho tenha revelado nuances importantes sobre os professores-gestores de instituições federais de ensino superior, com vistas a suprir a demanda contínua de conhecer o trabalho gerencial, nos seus mais diferentes níveis e ambientes organizacionais. 


\section{REFERÊNCIAS}

ALBERTI, V. Manual de história oral. $3^{\mathrm{a}}$ Ed. Rio de Janeiro: Editora FGV, 2005.

BANDEIRA-DE-MELLO, R. Softwares em pesquisa qualitativa. In: GODOI, C. K.; BANDEIRA-DEMELLO, R; SILVA, A. B. (Orgs.). Pesquisa qualitativa em estudos organizacionais: paradigmas, estratégias e métodos. 2 ed. São Paulo: Saraiva, 2010. p. 429-457.

BARDIN, L. Análise de conteúdo. São Paulo: Edições 70, 201 I.

BLEIKLIE, I; ENDERS, J.; LEPORI, B. Introduction: Transformation of universities in Europe. Higher Education, v.65, n. I, p. I-4, 2013.

BRAUN, D. Governance of universities and scientific innovation. In: MUSSELIN C.; TEIXEIRA P. (Eds.). Reforming Higher Education: Public policy design and implementation. London: Springer, 20I4. p. I45-I73.

CAMPOS, D.C. S. Competências gerenciais dos pró-reitores em uma instituição de ensino superior: um estudo de caso na Universidade Federal de Viçosa. 2007, I 59f. Dissertação (Mestrado em Administração) - Universidade Federal de Viçosa. Viçosa: 2007.

CAMPOS, D.C.S.; SOUZA, N.B.; CAMPOS,A.B., CUNHA, N.R.S.C; MAGALHAES, E.M.; CARVALHO, R. M.M. A. Competências Gerenciais Necessárias aos ProfessoresGerentes que atuam em pró-reitorias: o caso de uma Instituição Federal de Ensino Superior de Minas Gerais. In: Encontro da Associação Nacionais de Pós-Graduação e Pesquisa em Administração, 32., 2008, Rio de Janeiro. Anais... Rio de Janeiro:ANPAD, 2008.

CARROLL, J. B.; WOLVERTON, M. Who becomes a chair? In: W.
GMELCH,W.; SCHUH, J.H. (Eds.). The life cycle of a department chair. New Directions for Higher Education, n. 126, p. 3-10, 2004.

CARVALHO,T. Changing connections between professionalism and managerialism: case study of nursing in Portugal. Journal of Professions and Organization, v.2, n.I, p. I-I5, 2014.

CARVALHO; T.; BRUCKMANN, S. Reforming Portuguese Public Sector: a route from health to higher education. In: MUSSELIN C.; TEIXEIRA P. (Eds.). Reforming Higher Education: Public policy design and implementation. London: Springer, 20I4. p.83-102.

CHIZZOTTI, A. Pesquisa em ciências humanas e sociais. São Paulo: Cortez, 1991.

COMARÚ, P. Qualidade e Desenvolvimento Profissional. In: FRANCO, M. E. D. P.; MOROSINI, M. C. (Orgs.). Qualidade na Educação Superior: dimensões e indicadores. Porto Alegre: EDIPURCS, v. 4, 20II. p. 86-100.

CUNHA, L. A. Reforma universitária em crise: gestão, estrutura e território. In: TRINDADE, H. (Org.). Universidade em ruínas: na república dos professores. Porto Alegre: CIPEDES, 1999. p. I25-I 48.

CUNHA, M. I. A iniciação à docência universitária como campo de investigação: tendências e emergências contemporâneas. In: ISAIA, S. M. A; BOLZAN, D. P. V.; MACIEL, A. M. R. (Orgs.). Qualidade da educação superior: a Universidade como lugar de formação. v.2. Porto Alegre: EDIPUCRS, 2012, p. 20I-2I 2.

DEEM, R. The Knowledge Worker, the Manager-academic and the Contemporary UK University: New and Old Forms of
Public Management?. Financial Accountability \& Management. v.20,n. 2,p. 107-128,2004.

DEEM, R.; HILLYARD, S.; REED, M. Knowledge, higher education and the new managerialism: The Changing Management of UK Universities. Oxford: Oxford University Press, 2007.

ENDERS, J.; MUSSELIN, C. "Back to the Future? The Academic Professions in the 2 Ist Century". In: Higher Education to 2030. OECD Publishing, 2008, v. I, p. 125-250.

Universidade Federal de Minas Gerais. Belo Horizonte: 2007.

ÉSTHER, A. B. As Competências Gerenciais dos Reitores de Universidades Federais em Minas Gerais: a Visão da Alta Administração. In: Encontro Nacional de Administração Pública e Governança, 4.,2010, Vitória. Anais... Vitória: ANPAD, 2010.

ÉSTHER, A. B.; MELO, M. C. O. L. A construção da identidade gerencial dos gestores da alta administração de universidades federais em Minas Gerais. Cadernos EBAPE. BR, v. 6, n.I, p. 0I- 17, 2008.

FLECK, C. F.; PEREIRA, B.A. D. Professores e Gestores:Análise do perfil das competências gerenciais dos coordenadores de pós-graduação das instituições federais de ensino superior (IFES) do RS, BRASIL. Organizações \& Sociedade, v. 18, n.57, p. 285-30I, 201 I.

FROLICH, N; HUISMAN, J.; SLIPERSATER, S.; STENSAKER, B.; BÓTAS, P. C. P.A reinterpretation of institutional transformations in European higher education: strategising pluralistic organisations in multiplex environments. Higher Education, v. 65, n. I, p. 79-93, 2013.

GASKELL, G. Entrevistas individu- 
ais e grupais. In: BAUER, M. W.; GASKELL, G. Pesquisa qualitativa com texto, imagem e som: um manual prático. 8.ed. Petrópolis:Vozes, 2010. p. 64-89.

GODOY, A. S. Refletindo sobre critérios de qualidade da pesquisa qualitativa. Gestão. Org, v.3, n.2, p.8I-89, 2005.

HOFLING, E. M. Estado e políticas (públicas) sociais. Cadernos CEDES. v. 2I, n. 55, p. 30-4I, 200 I.

ISAIA, S. Professor universitário no contexto de suas trajetórias como pessoa e profissional. In: MOROSINI, M. (Org.). Professor do ensino superior: identidade, docência e formação. 2. ed. Brasília: Plano, 200 I, p. 35-60.

LE BOTERF, G. Desenvolvendo a competência dos profissionais. 3. ed. Porto Alegre:Artmed, 2003.

LOURENÇO, C.D.S.; LIMA, M.C.; NARCISO, E. R.P. Formação Pedagógica no Ensino Superior: o que diz a Legislação e a literatura em Educação e Administração? In: Encontro de Ensino e Pesquisa em Administração e Contabilidade, 4.,2013, Brasília. Anais.. Brasília: ANPAD, 2013.

MEEK, L.; GOEDEGEBUURE, L.; SANTIAGO, R.; CARVALHO, T. Introduction. In:

(Eds). The changing dynamics of higher education middle management, Dordrecht, Heidelberg, London, New York: Springer, 20I0, p. I-I4.

MELO, M. C. O. L.; LOPES, A. L. M.; RIBEIRO, J. M. O Cotidiano de Gestores entre as Estruturas Acadêmica e Administrativa de uma Instituição de Ensino Superior Federal de Minas Gerais. Revista Organizações em Contexto, v. 9, n. 17, p. 205-227, 2013.

MINAYO, M. C. de S. O desafio do conhecimento: pesquisa qualitativa em Saúde. 8. ed. São Paulo:
Hucitec, 2004.

MIRANDA, A. R. A. Um estudo sobre a dinâmica identitária de professoras gerentes de uma universidade pública. 2010.162 f. Dissertação (Mestrado em Administração) - Universidade Federal de Lavras. Lavras: 2010.

MORAES, L.V. dos S. de. A trajetória de mulheres que se tornaram reitoras em instituições de ensino superior no Estado de Santa Catarina. 2008. 240 f. Tese (Doutorado em Engenharia de Produção) -Universidade Federal de Santa Catarina. Florianópolis: 2008.

MOROSINI, M. C. Docência universitária e os desafios da realidade nacional. In:

(Org.). Professor do Ensino Superior: Identidade, Docência e Formação. v. I. Porto Alegre: INEP, 2000, p. II-20.

MOROSINI, M. C.; BITTAR, M.Verbete Política Pública. In: FRANCO, M. E. D. P.; BITTAR, M. (Org.) Enciclopédia de pedagogia universitária, Porto Alegre: RIES/ INEP, 2006.

MOZATTO, A. R.; GRZYBOVSKI, D. Análise de Conteúdo como Técnica de Análise de Dados Qualitativos no Campo da Administração: Potencial e Desafios. Revista de Administração Contemporânea, v. 15, n. 4, p. 731-747, 2011.

MUSSELIN, C. Redefinition of the relationships between academics and their university. Higher Education, v. 65, n.I p.25-37, 2013.

NEAVE, G. The Evaluative State Reconsidered. European Journal of Education, v. 33, n. 3, p. 265 284, 1998.

O'CONNOR, P.; CARVALHO, T. Different or similar: constructions of leadership by senior managers in Irish and Portuguese universities.
Studies in Higher Education, v.40, n.9, p. I-14, 2015.

OLIVEIRA, D. P. R. Estrutura organizacional: uma abordagem para resultados e competitividade. São Paulo:Atlas, 2006.

SANTIAGO, R.; CARVALHO,T. Managerialism Rhetoric in Portuguese Higher Education. Minerva, v. 50, n. 4, p. 5II-532, 2012.

SANTIAGO, R.; CARVALHO, T. Mudança no conhecimento e na profissão acadêmica em Portugal. Cadernos de Pesquisa, v. 4I, n. I43, p. 402-426, 20 I I.

SANTIAGO, R.; CARVALHO,T.;AMARAL,A.; MEEK, L. Changing patterns in the middle management of higher education institutions: The case of Portugal. Higher Education v. 52, n.2, p. 21 5-250, 2006.

SANTOS, K. C. G.; HELAL, D. H. O Estágio Docente e o Desenvolvimento de Competências: um Estudo no Programa de Pós-Graduação em Administração da Universidade Federal da Paraíba. In: IV Encontro de Ensino e Pesquisa em Administração e Contabilidade, 4.,.2013, Brasília. Anais.. Brasília:ANPAD, 2013.

SILVA, F. M.V.A transição para a gestão universitária: o significado das relações interpessoais. Revista de Administração FACES Journal, v. II, n. 4, p. 72-9I, 2012. SILVA, M. A. A aprendizagem de professores da Universidade Federal de Santa Catarina para dirigir as unidades universitárias. 2000. 268f. Tese (Doutorado em Engenharia da Produção) - Universidade Federal de Santa Catarina. Florianópolis; 2000.

SILVA, F. M. V.; CUNHA, C. J. C.A. A Transição de contribuidor individual para líder: a experiência vivida pelo professor universitário. Revista GUAL, v. 5, n. I, p. I45- 
I7I, 2012.

SILVA, A. B.; COSTA, F. J. Itinerários para o desenvolvimento da competência docente na pós-graduação Stricto Sensu em Administração. Revista Economia \& Gestão, v. |4, n. 34, 20 |4.

SOARES, S. R.; CUNHA, M. I. Formação do professor: a docência universitária em busca de legiti- midade. Salvador: EDUFBA, 2010. VALENTIM; I.V.L.; EVANGELISTA, S. T. Para onde vai o ensino universitário federal brasileiro? Pistas e subjetivações a partir da lei 12.772/2012. In: Coloquio de Gestión Universitaria en Américas.3.,2013, Buenos Aires. Anais...Buenos Aires: INPEAU, 2013.
VIEIRA, M. M. F. Por uma Boa Pesquisa (Qualitativa) em Administração. In:VIEIRA, M. M. M. F.; ZOUAIN, D. M. (Orgs). Pesquisa Qualitativa em Administração. Rio de Janeiro: FGV, 2004. p. I3-28.

ZABALZA, M. A. O ensino universitário: seu cenário e seus protagonistas. Porto Alegre: Artmed, 2007. 